\title{
Mapping Water Vulnerability of the Yangtze River Basin: 1994-2013
}

\author{
Fengyun Sun ${ }^{1,2} \cdot$ Wenhui Kuang ${ }^{3} \cdot$ Weining Xiang ${ }^{2} \cdot$ Yue Che $^{2}$
}

Received: 28 February 2016 / Accepted: 9 August 2016 / Published online: 12 September 2016

(C) Springer Science+Business Media New York 2016

\begin{abstract}
A holistic understanding of the magnitude and long-term trend of water vulnerability is essential for making management decisions in a given river basin. Existing procedures to assess the spatiotemporal dynamic of water vulnerability in complex mega-scale river basins are inadequate; a new method named ensemble hydrologic assessment was proposed in this study, which allows collection of data and knowledge about many aspects of water resources to be synthesized in a useful way for vulnerability assessment. The objective of this study is to illustrate the practical utility of such an integrated approach in examining water vulnerability in the Yangtze River Basin. Overall, the results demonstrated that the ensemble hydrologic assessment model could largely explain the spatiotemporal evolution of water vulnerability. This paper improves understanding of the status and trends of water resources in the Yangtze River Basin.
\end{abstract}

Keywords Water vulnerability $\cdot$ Integrated hydrologic assessment · SWAT $\cdot$ IHA $\cdot$ FDC $\cdot$ Yangtze River Basin

Electronic supplementary material The online version of this article (doi:10.1007/s00267-016-0756-5) contains supplementary material, which is available to authorized users.

Yue Che

yche@des.ecnu.edu.cn

1 School of Geographic Sciences, East China Normal University, Shanghai 200241, China

2 Shanghai Key Laboratory of Urbanization and Ecological Restoration, East China Normal University, Shanghai 200241, China

3 Institute of Geographic Sciences and Natural Resources Research, Chinese Academy of Sciences, Beijing 100101, China

\section{Introduction}

Many rivers around the world experience dramatic changes in flow, reducing their natural ability to adjust to and absorb disturbances (Palmer et al. 2008, 2009). The sustainability of water resources is an increasingly important concern against the backdrop of burgeoning water demand for environmental, domestic, industrial, and agricultural uses to sustain the 9.4-10 billion people expected in 2050 (United Nations 2015). The issue has become more challenging under the circumstance of shrinking water resources (Singh 2014; Singh and Panda 2012) due to both climate variability (Chen et al. 2007; Ravazzani et al. 2015; Vörösmarty et al. 2000) and anthropogenic disturbance (Botter et al. 2010; Mejía et al. 2015; Wang et al. 2013). The supply-demand imbalance in the water sector calls for more effective water management practices ( $\mathrm{Xi}$ and Poh 2015). However, if detailed status of water resources is uncertain to managers, both suppliers and demanders, then effective allocation among competing uses can be difficult (Sunday et al. 2014).

Water vulnerability (i.e. physical threats as well as human capability to cope with) assessment is a longstanding concern to water managers, who are also committed to the basin management plans for Integrated Water Resources Management (Plummer et al. 2013; Sullivan 2011). Interest in assessing water vulnerability dates back to the 1920s; more than 50 approaches are available for this purpose, according to systematic literature reviews by Plummer et al. (2012) and de Grosbois and Plummer (2015). Composite index, referred as multiple individual indicators in providing a measure of a complex and multidimensional issue, is the general form of the myriad of water vulnerability assessment tools (Sullivan et al. 2010; Sullivan and Meigh 2007). However, reduction of indicators due to data availability, cost-effectiveness, and desire to minimize the 
number of indicators could damage the conceptual foundation of the existing assessing measurements (de Grosbois and Plummer 2015). Moreover, comprehensiveness, simplicity, and applicability are important considerations of existing water vulnerability indicators (Chaves and Alipaz 2007; Dickson et al. 2016; Hamouda et al. 2009). However, insufficient attention has been paid to the dynamic and comparability of these indicators in the construction process, which can be extremely important in monitoring the evolution of water status in long period. Furthermore, administrative boundaries were usually adopted in water vulnerability assessment. For example, indicators have been developed to assess water security based on communities (Alessa et al. 2008; Cohen and Sullivan 2010), municipalities (Sullivan 2011) as well as counties (Lawrence et al. 2002; Sullivan et al. 2010). However, hydrologic processes are mainly affected by the spatial variability of soils, topography, land use/cover, climate changes within the biophysical boundaries of water catchment instead of political governance (Nyerges 2002). The unique hydrologic characteristics of each evaluation unit cannot be addressed when using administrative boundaries. Thus, tools that enable holistic understanding and indeed visualization of spatiotemporal dynamics of water vulnerability should also be developed at sub-basin level within the biophysical boundaries. The field of hydrology has witnessed a wealth of developments (Bierkens 2015; Dawadi and Ahmad 2013; Fukunaga et al. 2015; Pradhanang et al. 2013; Rouholahnejad et al. 2014; Shrestha et al. 2014; Xi and Poh 2015). Advances in methodologies, geo-informatics, computational intelligences, and modeling approaches have enriched the scope and role of the information available and are potentially useful to water assessors (Lahoz and De Lannoy 2014).

The Yangtze River (YR, $6300 \mathrm{~km}$ in length), the longest in Asia, runs eastward across central and eastern China from the Qinghai-Tibet Plateau. The Yangtze River Basin (YRB, 1.81 $\times 10^{6} \mathrm{~km}^{2}$ ), the third-largest drainage basin on Earth, plays an important role in social and economic developments in China. Nowadays the YRB has already been home to 440 million people, over $33 \%$ of China's population, and contributed $40 \%$ of the total GDP (Gao et al. 2012; Guan et al. 2015). In September 2014, the State Council of China (2014) launched a major new initiative for strengthening the development of the Yangtze River Economic Super-zone. The guidance ushered in a new era of social and economic development for the YRB. The selection of the YRB as our study area is motivated by the great challenge imposed by water resources on the social-economic development of the YRB. Characterizing possible changes in flow extremes and assessing variability in water availability and consumption are critical to the sustainable development of the YRB, but have not been systematically addressed in the literature.
Our main goal in this study is to facilitate holistic water vulnerability assessment at sub-basin scale and to demonstrate the practical utility of such an integrated approach in quantifying the water vulnerability in the YRB. We considered water vulnerability with respect to sustainable freshwater resources only. We believe the ensemble hydrologic assessment (EHA) model can provide a useful approach in which data and knowledge collected at many aspects of river basin can be synthesized by bringing together the full range of powerful tools and understanding. This will lead to a water vulnerability assessment that is useful to water users, hydrologists, and vulnerability assessors.

\section{Data and Method}

This section includes six subsections. The first subsection gives information about the study area, while the remaining five subsections are stepwise procedures adopted to construct the EHA model for the assessment of water vulnerability. Strategies and algorithms of the EHA framework used in each step are depicted in Fig. 1. Step 1 (Section "Hydrologic modeling") uses a hydrologic model to represent the physical processes observed in the real world. Step 2 (Section "Assessment of hydrologic alteration") considers both hydrologic alteration in water yield and flow regime. Step 3 (Section "Assessment of available water resources") derives available water from the flow duration curves (FDCs) at the outlet of each sub-basin. Step 4 (Section "Estimation of water consumption") estimates water consumption of both ecosystems and livelihoods. Step 5 (Section "Evaluation of water vulnerability") employs a space-time matrix to display water vulnerability with respect to supply-demand relationships between available and consumed water resources.

\section{Study Area}

Generally, the YRB is partitioned into 12 sub-basins based on the large tributaries that flow into it (Fig. 2). Sub-basins information including names, acronyms, and area ratios are given in Table 1 . The sub-basin TL was not considered in this study, since this sub-basin is surrounded by the sea on three sides, which would lead to the inaccuracy in determination of flow outlets as well as hydrologic simulation.

\section{Hydrologic Modeling}

To determine the flow regime, Soil and Water Assessment Tool (SWAT) was adopted in this paper, which is one of the most commonly used and well-performing river basin scale models. SWAT can be used to predict water yields in large, 
Fig. 1 Ensemblehydrologic assessment (EHA) algorithm

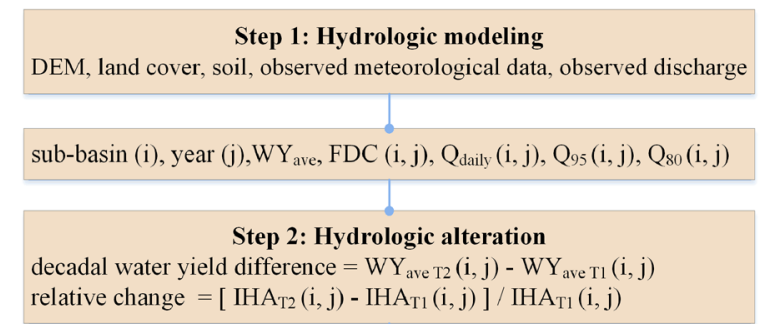

\section{Subscripts:}

$\mathrm{i}=$ sub-basin ID

$\mathrm{j}=$ year

ave $=$ average annual water yield

all $=$ total water consumption

$\mathrm{L} 1=$ eco-environmental water

$\mathrm{L} 2=$ domestic water

L3 = agro-industry water

daily $=$ daily value

$95=95 \%$ reliability

$80=80 \%$ reliability

$\mathrm{T} 1=$ from 1994 to 2003

T2 = from 2004 to 2013
Key variables:

$\mathrm{WY}=$ water yield

$\mathrm{FDC}=$ flow duration curve

$\mathrm{Q}=$ flow rate

IHA = indicators of hydrologic alteration

$\mathrm{A}=$ available water

$\mathrm{C}=$ consumed water

$\Sigma=$ sum over sub-basin $\mathrm{i}$, year $\mathrm{j}$

time $=$ total duration of the flow
Step 4: Water consumption $\mathrm{C}_{\mathrm{all}}(\mathrm{i}, \mathrm{j})=\mathrm{C}_{\mathrm{L} 1}(\mathrm{i}, \mathrm{j})+\mathrm{C}_{\mathrm{L} 2}(\mathrm{i}, \mathrm{j})+\mathrm{C}_{\mathrm{L} 3}(\mathrm{i}, \mathrm{j})$ $\mathrm{C}_{\mathrm{L} 1}(\mathrm{i}, \mathrm{j})=$ eco-environment

$\mathrm{C}_{\mathrm{L} 2}(\mathrm{i}, \mathrm{j})=$ household

$\mathrm{C}_{\mathrm{L} 3}(\mathrm{i}, \mathrm{j})=$ agriculture + industry
$A_{\text {all }}(i, j)=\Sigma Q_{\text {daily }}(i, j) \times$ time

$A_{L 1}(i, j)=\sum Q_{95}(i, j) \times$ time

$A_{L 2}(i, j)=\Sigma Q_{80}(i, j) \times$ time $-A_{L 1}(i, j)$

$A_{L 3}(i, j)=A_{a l l}(i, j)-\left[A_{L 1}(i, j)+A_{L 2}(i, j)\right]$

Step 5: Water budget (WB)
$\mathrm{WB}_{\mathrm{all}}=\mathrm{A}_{\text {all }} / \mathrm{C}_{\mathrm{all}} ; \quad \mathrm{WB}_{\mathrm{L} 1}=\mathrm{A}_{\mathrm{L} 1} / \mathrm{C}_{\mathrm{L} 1} ; \quad \mathrm{WB}_{\mathrm{L} 2}=\mathrm{A}_{\mathrm{L} 2} / \mathrm{C}_{\mathrm{L} 2} ; \quad \mathrm{WB}_{\mathrm{L} 3}=\mathrm{A}_{\mathrm{L} 3} / \mathrm{C}_{\mathrm{L} 3}$

Water vulnerability (WV)

If $\mathrm{WB} \leqslant 0.1, \mathrm{WV}=$ low; $\quad$ If $0.1<\mathrm{WB} \leqslant 0.2, \mathrm{WV}=$ moderate;

If $0.2<\mathrm{WB} \leqslant 0.4, \mathrm{WV}=$ medium-high; $\quad$ If $\mathrm{WB}>0.4, \mathrm{WV}=$ high

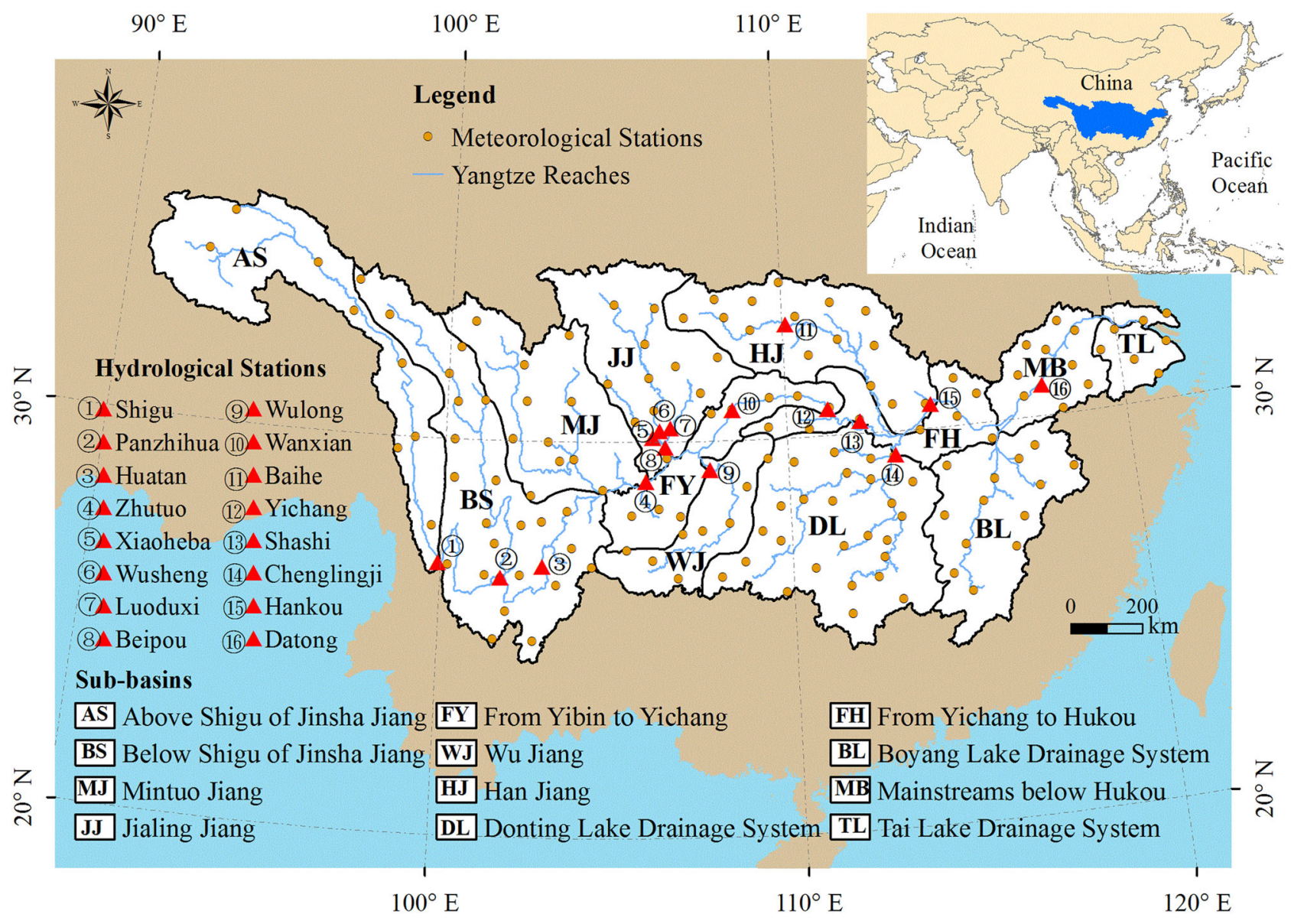

Fig. 2 The YRB location map 
complex watersheds with varying soil, land use, and management conditions over long periods of time (Arnold et al. 2013; Neitsch et al. 2009). For modeling purpose, SWAT model partitions river basin into a number of watersheds allowing the user to spatially compare different areas of the

Table 1 Sub-basin information of the YRB

\begin{tabular}{llrr}
\hline Acronyms & Names & Area $\left(\mathrm{km}^{2}\right)$ & Area ratios \\
\hline AS & Above Shigu of Jinsha Jiang & $216,409.14$ & $12.15 \%$ \\
BS & Below Shigu of Jinsha Jiang & $264,571.96$ & $14.86 \%$ \\
MJ & Mintuo Jiang & $168,087.97$ & $9.44 \%$ \\
JJ & Jialing Jiang & $164,564.14$ & $9.24 \%$ \\
WJ & Wu Jiang & $86,357.27$ & $4.85 \%$ \\
FY & From Yibin to Yichang & $96,124.99$ & $5.40 \%$ \\
DL & Donting Lake Drainage & $256,270.68$ & $14.39 \%$ \\
& System & & \\
HJ & Han Jiang & $168,383.23$ & $9.46 \%$ \\
BL & Boyang Lake Drainage & $156,289.41$ & $8.78 \%$ \\
& System & $83,651.28$ & $4.70 \%$ \\
FH & From Yichang to Hukou & $86,257.12$ & $4.84 \%$ \\
MB & Mainstreams below Hukou & $33,665.93$ & $1.89 \%$ \\
TL & Tai Lake Drainage System & & \\
\hline
\end{tabular}

river basin. The hydrologic cycle simulated by SWAT is based on the water balance equation:

$$
S W_{t}=S W_{0}+\sum_{i=1}^{t}\left(R_{d a y}-Q_{\text {surf }}-E_{a}-W_{\text {seep }}-Q_{g w}\right)
$$

where $S W_{t}$ is the final soil water content $(\mathrm{mm}), S W_{0}$ is the initial soil water content on day $i(\mathrm{~mm}), t$ is the time (days), $R_{\text {day }}$ is the amount of precipitation on day $i(\mathrm{~mm}), Q_{\text {surf }}$ is the amount of surface flow on day $i(\mathrm{~mm}), E_{a}$ is the amount of evapotranspiration on day $i(\mathrm{~mm}), W_{\text {seep }}$ is the amount of water entering the vadose zone from the soil profile on day $i(\mathrm{~mm}), Q_{g w}$ is the amount of return flow on day $i(\mathrm{~mm})$.

SWAT is a comprehensive model that requires a diversity of information in order to run. Input data used in the modeling process were: (1) Digital elevation model, obtained from the Advanced Spaceborne Thermal Emission and Reflection Radiometer with a 1 arc-second grid of elevation postings (URL: http://gdem.ersdac.jspacesystems. or.jp) (Fig. 3a). (2) Land cover data for 2010, derived from GlobeLand30, with a spatial resolution of 1 arc-second (URL: http://www.globallandcover.com) (Fig. 3b). (3) Soil properties collected from Harmonized World Soil Database of the Food and Agriculture Organization of the United Nations, the Harmonized World Soil Database is a
Fig. 3 Digital elevationmodel, land cover, and soil map of the YRB
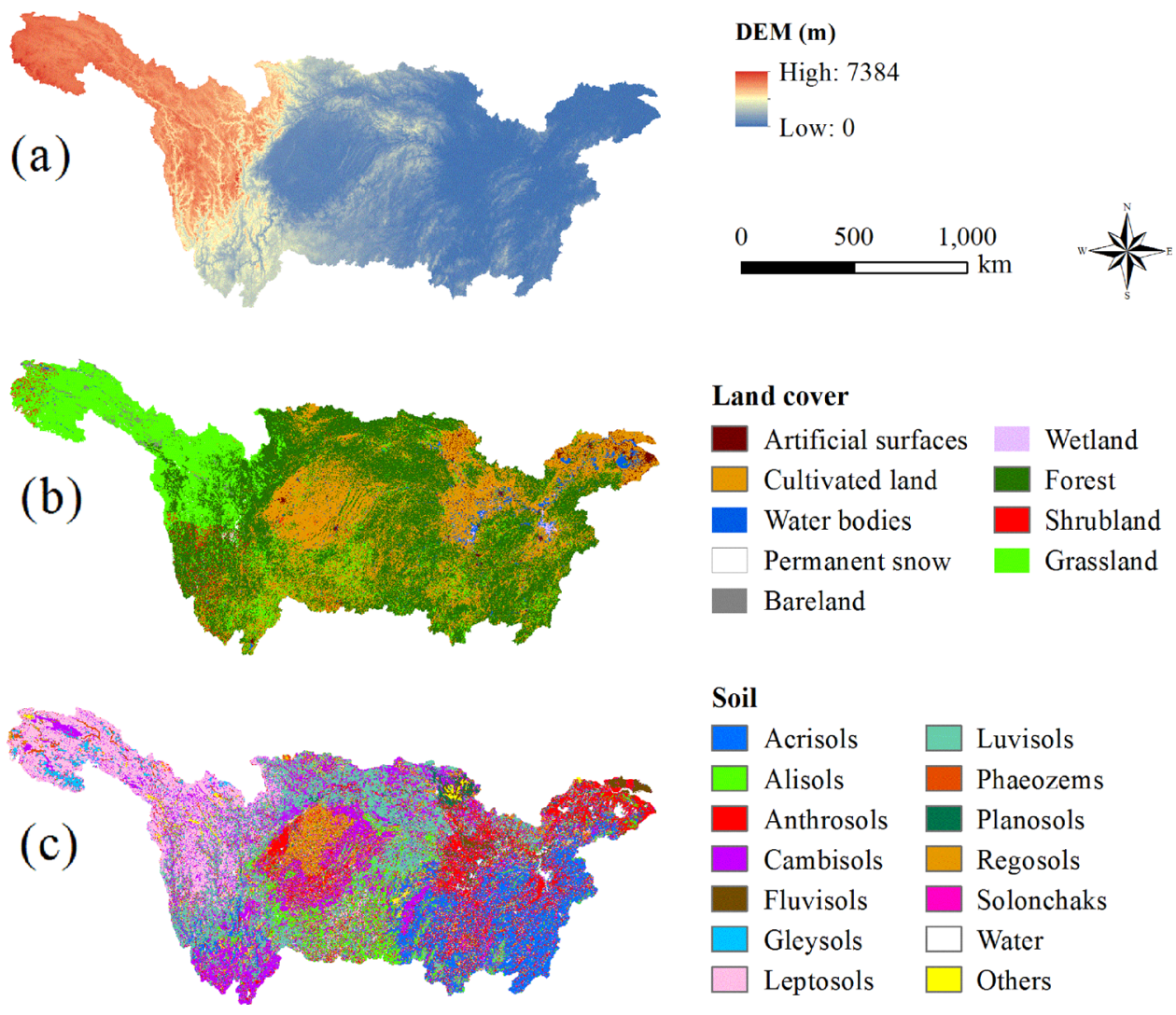
Table 2 Summary of model performance assessment

\begin{tabular}{|c|c|c|c|c|c|}
\hline \multirow[b]{2}{*}{ Station name } & \multirow[b]{2}{*}{ Station No. } & \multicolumn{2}{|c|}{ Calibration } & \multicolumn{2}{|c|}{ Validation } \\
\hline & & $R^{2}$ & NS & $R^{2}$ & NS \\
\hline Shigu & 1 & 0.73 & 0.70 & 0.72 & 0.68 \\
\hline Panzhihua & 2 & 0.74 & 0.58 & 0.73 & 0.56 \\
\hline Huatan & 3 & 0.80 & 0.59 & 0.81 & 0.59 \\
\hline Zhutuo & 4 & 0.80 & 0.70 & 0.76 & 0.66 \\
\hline Xiaoheba & 5 & 0.61 & 0.23 & 0.68 & 0.68 \\
\hline Wusheng & 6 & 0.62 & 0.56 & 0.66 & 0.66 \\
\hline Luoduxi & 7 & 0.64 & 0.61 & 0.56 & 0.54 \\
\hline Beipou & 8 & 0.72 & 0.70 & 0.73 & 0.72 \\
\hline Wulong & 9 & 0.74 & 0.73 & 0.67 & 0.50 \\
\hline Wanxian & 10 & 0.83 & 0.79 & 0.75 & 0.70 \\
\hline Baihe & 11 & 0.62 & 0.21 & 0.68 & 0.46 \\
\hline Yichang & 12 & 0.82 & 0.79 & 0.69 & 0.60 \\
\hline Shashi & 13 & 0.84 & 0.80 & 0.71 & 0.42 \\
\hline Chenglingji & 14 & 0.72 & 0.70 & 0.83 & 0.81 \\
\hline Hankou & 15 & 0.91 & 0.91 & 0.83 & 0.78 \\
\hline Datong & 16 & 0.93 & 0.91 & 0.90 & 0.86 \\
\hline
\end{tabular}

30 arc-second raster database (URL: http://data.fao.org/ map) (Fig. 3c). (4) Daily observed meteorological data, including precipitation, temperature (min and max), average wind speed, relative humidity, solar radiation of 148 stations during the period 1992-2013, obtained from China Meteorological Data Sharing Service System (URL: http:// cdc.nmic.cn) (Fig. 2). (5) Monthly discharge data from 1994 to 2013 observed at 16 stations used to calibrate and validate the performance of the SWAT model, provided by the Bureau of Hydrology, Changjiang River Water Resources Commission (CWRC) (Fig. 2).

The performance of SWAT was evaluated on the basis of statistical relationship between the observed flow and the model output. $R^{2}$ was used to describe the proportion of the variance in measured data explained by the modeled data. $R^{2}$ ranges between 0 and 1 , the higher the value the better the fit, and values greater than 0.5 are considered acceptable (Moriasi et al. 2007). Nash-Sutcliffe coefficient (NS) is a normalized statistic that measures the relative magnitude of the residual variance compared to the measured data variance, which ranges from $-\infty$ to 1 , with the performance rating acceptable if values between 0 and 1 (Castillo et al. 2014; Moriasi et al. 2007).

The model was calibrated using observed discharge at 16 stations for 14 years (1994-2007). Another six-year (20082013) simulation was used for validation separately. Results of the calibration and validation process were summarized in Table 2 and supplementary Figures 1-4. Statistical results of $R^{2}$ and NS values indicated a good consistency between simulated and observed data both in the calibration and validation periods. The modeling performance was particularly good for the Datong station (station no. 16), which is near to the whole basin outlet. $R^{2}$ and NS for the calibration period were 0.93 and 0.90 respectively. As for the validation period, the values were 0.93 and 0.86 respectively. Accordingly, SWAT had quite accurately reproduced the rainfall-runoff process for the YRB. The model established in this study was suitable to investigate hydrology and to assist in addressing water resource vulnerability prevailing in the YRB.

\section{Assessment of Hydrologic Alteration}

To explicitly identify the hydrologic alteration in both water yield and flow regime, we divided the entire period of analysis into two consecutive, equal durations (i.e. from 1994 to 2003, and from 2004 to 2013). Firstly, average annual water yields at each sub-basin were simulated and compared between these two time intervals. Secondly, the indicators of hydrologic alteration (IHA) were used to determine the alteration in flow regime for each sub-basin. Thirdly, the relative change method was used to compare IHA metrics variation between these two time intervals.

The IHA method, created by Richter et al. (1996), is a representative, multi-parameter suite of hydrologic indicators that uses regressions of 33 parameters with time to assess alterations of flow magnitude, duration, timing, frequency, and rate of hydrologic change (Richter et al. 1997, 1998, 2003). Definition and calculation algorithm of the parameters can be found in Indicators of Hydrologic Alteration Users Manual (https://www.conservationgateway. org/Documents/IHAV7.pdf). This method is based either upon hydrologic data available within an ecosystem or upon model-generated data (Gao et al. 2009; Mathews and Richter 2007). "Number of zero-flow days" was eliminated in this study, because zero-flow day did not occur for most of the sub-basin outlets during the study period.

\section{Assessment of Available Water Resources}

Flow duration curve illustrates the relationship between the frequency and magnitude of flow $(Q)$ over a considered period for a particular river basin (Castellarin et al. 2004; Vogel and Fennessey 1994; Vogel and Fennessey 1995). Each value of $Q$ has a corresponding exceedance probability $p$, and an FDC is simply a plot of $Q_{p}$, the $p$ th quantile or percentile of daily flow vs. exceedance probability $p$, the quantile $Q_{p}$ is a function of observed flow, where $p$ is defined by

$$
\begin{aligned}
& p=1-P\{Q \leq q\} \\
& p=1-F_{Q}(q)
\end{aligned}
$$


To determine the volume of available water resources, yearly FDCs were first constructed using daily-simulated flow at the outlet of each sub-basin. Generally, the ecoenvironmental sector share the top of the priority for water usage, followed by the household, agricultural, and industrial sector. According to this order of priority and flow exceedance rationale, available water resources were then divided into three different blocks: eco-environmental available water $\left(\leq Q_{95}\right)$, domestic available water $\left(Q_{80}\right.$ to $\left.Q_{95}\right)$, and agro-industrial available water $\left(>Q_{80}\right)$. Assessment of water resources in blocks of water sectors was applied both by Draper et al. (2003) and Dessu et al. (2014). The total available water within each sub-basin is calculated by adding both water yield of the sub-basin and the inflow from upstream sub-basins.

\section{Estimation of Water Consumption}

Water consumption data were available in this study from two major sources. Data from 2003 to 2013 were from water consumption statistics reports of the YRB released by the CWRC on a yearly basis since 2003. Water consumption in this report is calculated as the gross water (including water conveyance loss) that assigned to water users. Four major consumption sectors are included in the statistics report: eco-environment, human population, agriculture, and industry. Eco-environmental water is referred as water provided to city environment, river, lake, or wetland by artificial cultivation measures. Water used for human population includes urban domestic water consumption, urban public water consumption, and rural domestic water consumption. Agricultural water consumption includes livestock water consumption and irrigation of farmland, forest, orchard, and grassland. Industrial water is referred to the newly obtained water, while repeated use of water within the enterprise is not included. To facilitate estimation of water consumption, water collected for different sectors was regrouped into eco-environmental water consumption (ecological and environmental water use), domestic water consumption, and agro-industrial water consumption (agricultural and industrial water use).

Data from 1994 to 2002 were estimated using Grey prediction theory. Techniques that generate reliable estimated water consumption data are needed to mitigate the drawback of unavailable long periods of water consumption data. Grey prediction theory (Deng 1982) is a multidisciplinary and generic theory that deals with grey systems. Grey Systems is referred as the systems that lack information, such as structure message, operation mechanism, and behavior document (Deng 1989). GM $(1,1)$ is one of the most frequently used grey forecasting models, pronounced as "Grey Model First Order One Variable". The process of constructing a GM $(1,1)$ model is initiated by formatting accumulated generation operation (Deng 1989), with the main purpose to reduce the randomness of the data. Then, the GM $(1,1)$ model can be constructed by establishing a first-order differential equation, aided by using the least square method, the fitted and predicted series then can be obtained from the constructed GM $(1,1)$ model. Detailed constructing process and formulas can be found in (Akay and Atak 2007; Deng 1989; Hsu and Chen 2003; Kayacan et al. 2010).

\section{Evaluation of Water Vulnerability}

Water budget (WB) was assessed for available eco-environmental water (L1), domestic water (L2), agro-industrial water (L3), and total water (all) volume with respect to their corresponding consumption. The WB ratio determines the degree of sustainable water supply and provides an indicator of water vulnerability (WV), which could be classified into four categories. Values lower than 0.1 are assigned for low $\mathrm{WV}$, on the order of 0.1 to 0.2 are defined as moderate $\mathrm{WV}$, whereas 0.2 to 0.4 indicate medium-high $\mathrm{WV}$, those greater than 0.4 are assigned for high WV which reflect conditions of severe water limitation (Shiklomanov 1996; Vörösmarty et al. 2000). A space-time matrix was used to display results of water vulnerability for readily comprehensiveness and decision-making.

\section{Results}

\section{Hydrologic Alteration}

\section{Alteration in Water Yield}

Annual precipitation and water yield at 11 sub-basins of the YRB from 1994 to 2013 were calculated (Fig. 4). Based on simulation results, water yield varied greatly with location. Sub-basins in the downstream yielded more water than those in the upper reach. The lowest average water yield appeared in sub-basin AS $(114.9 \mathrm{~mm})$, followed by sub-basin BS (319.4 mm) and HJ (391.9 mm). While four sub-basins which share the highest water yield, namely, sub-basin BL (1097.1 mm), DL (937.0 mm), FH (835.0 $\mathrm{mm}), \mathrm{MB}(820.6 \mathrm{~mm})$, are located in the downstream of the YRB. Furthermore, water yield changed significantly with time. Standard deviations of the 11 sub-basins over 20 years varied from 33.54 (sub-basin AS) to 251.64 (sub-basin BL). Four sub-basins that had the largest variation were subbasin BL (251.64), FH (227.11), MB (194.82), DL (182.54) that located in the downstream of the YRB. Moreover, there was a very strong, positive correlation of 0.98 between annual precipitation and water yield (Pearson correlation, $N=220, P<0.001)$. 
Fig. 4 Annual precipitation (a) and water yield (b) of 11 subbasins in the YRB from 1994 to 2013
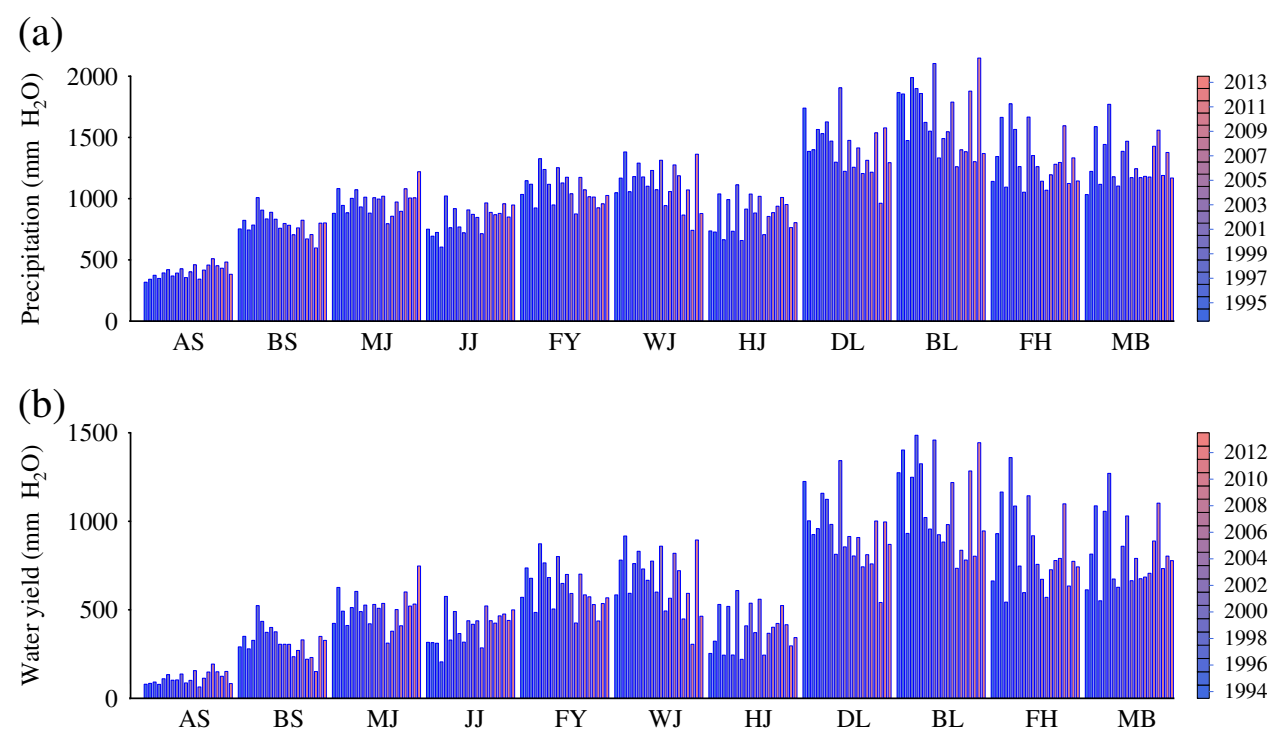

(a)

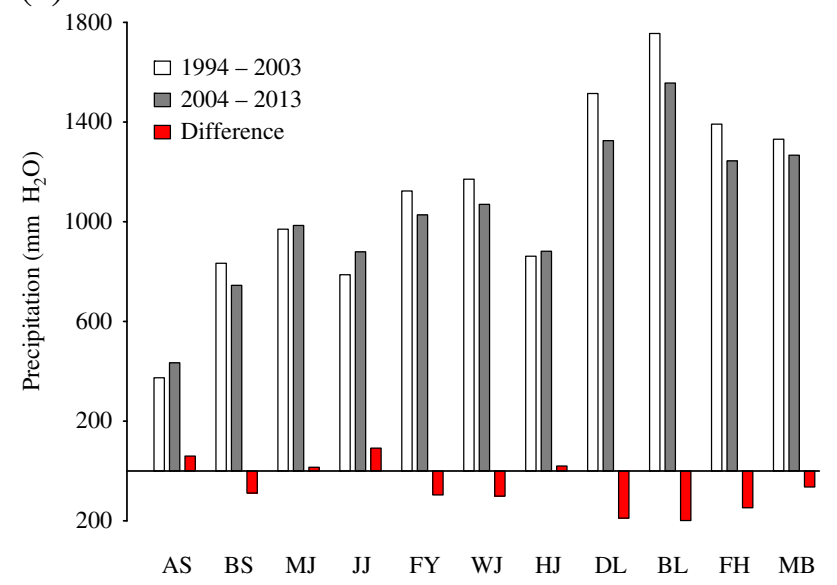

(b)

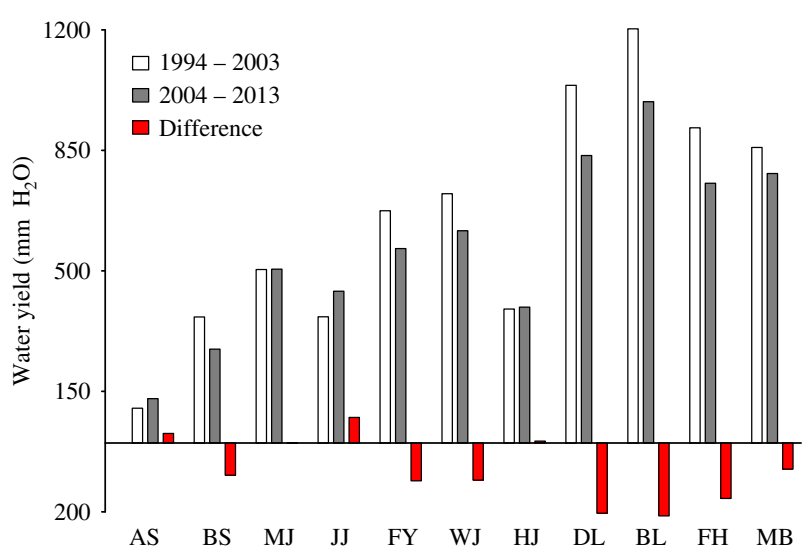

Fig. 5 Decadal average precipitation (a) water yield (b) and difference between two decades

Differences in annual precipitation and water yield between periods of 1994 to 2003 and 2004 to 2013 at 11 sub-basins were illustrated in Fig. 5. An upward trend in water yield was observed in four sub-basins: JJ $(+74.30 \mathrm{~mm}), \mathrm{AS}(+27.77 \mathrm{~mm}), \mathrm{HJ}(+5.50 \mathrm{~mm})$, and $\mathrm{MJ}$ $(+1.10 \mathrm{~mm})$. While water yield of the remaining seven subbasins decreased in the second decade compared to the first decade. Sub-basin BL had the most dramatic annual decrease $(-211.72 \mathrm{~mm})$, followed by sub-basin DL $(-203.86 \mathrm{~mm})$ and sub-basin FH $(-161.06 \mathrm{~mm})$. The downward trend in water yield averaged $-137.6 \mathrm{~mm}$, which is much more dramatic than the upward trend $(+27.2 \mathrm{~mm})$.

The central tendency and variability of annual precipitation and water yield are depicted by boxplots in Fig. 6 . Average precipitation and water yield decreased in the second decade compared to the first decade in sub-basins
BS, FY, WJ, DL, BL, FH, and MB (indicated by the median). Enhanced decadal variability in precipitation appeared in sub-basins WJ and BL (indicated by the size of the boxes), while variability in other sub-basins remained stable or reduced. Comparatively, water yield showed larger variability in sub-basins AS, MJ, WJ, and BL. Moreover, there were more outliers in water yield (seven) than in precipitation (two), and all the outliers appeared in the second decade.

\section{Alteration in Flow Regime}

Notable decadal variability was found in the above analysis, which necessitates a detailed examination of changes in flow regime. In this subsection, relative deviation percentage of the IHA parameters was used to illustrate the 
(a)

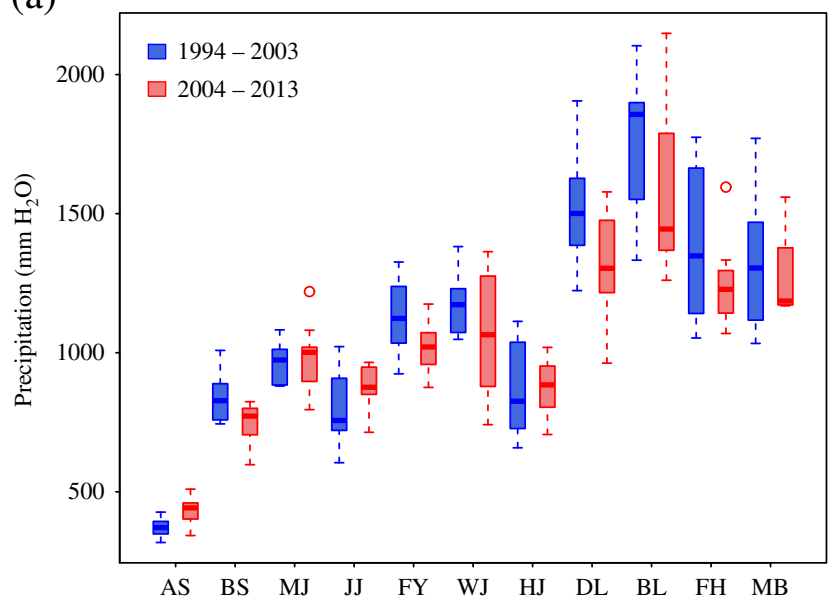

(b)

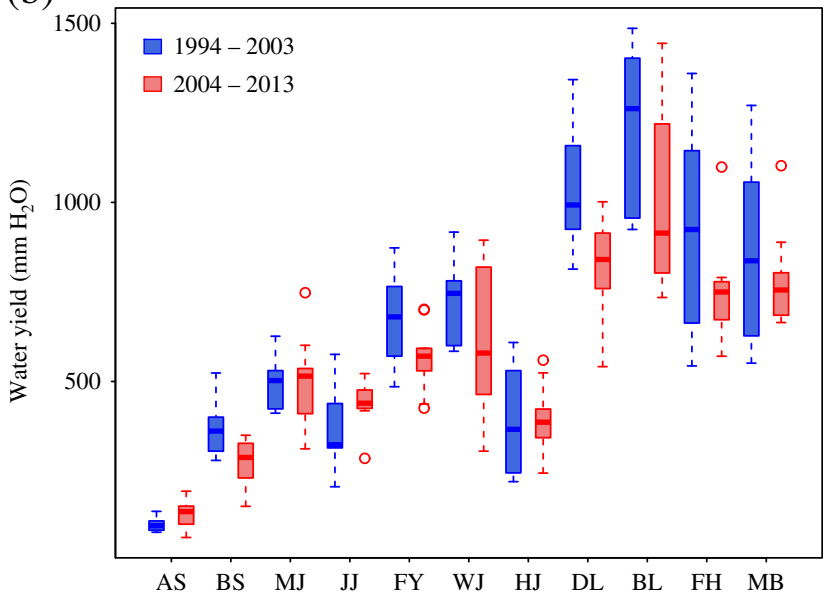

Fig. 6 Boxplot of annual precipitation (a) and water yields (b) in two decades

differences in mean variation between periods 1994-2003 and 2004-2013 (Table 3).

Relative differences between means were volatile among individual attributes of 11 sub-basins, fluctuating between $+45.31 \%$ (mean flow in February of sub-basin AS) and $-62.08 \%$ (base flow index of sub-basin AS). There were 33 values showing a relative change exceeding $\pm 30 \%$, and 92 values showing a relative change between +15 to $+30 \%$ and -30 to $-15 \%$.

In terms of IHA group 1, the most dramatic shift $(31.29 \%)$ occurred in sub-basin AS, which saw a significant increase in mean flow from July to February and an evident downward trend from April to June. Sub-basin BS had a group average of 17.22 with all the monthly mean flows decreased except for May. Sub-basin JJ ranked second in terms of group average, whose monthly mean flows were all in an increasing trend except for May. An increasing trend was also observed in sub-basin HJ. Nevertheless, mean flow experienced a general decline in 9 out of 11 sub-basins, especially the all-time negative deviation in four sub-basins (sub-basin DL, BL, FH, and MB) that located in the lower reach of the YRB.

As to IHA group 2, the most extreme situation also occurred in AS (34.88\%); all minimum flow durations along with base flow index (7-day minimum flow/mean flow for year) suffered a noticeable decline. By contrast, all maximum flow durations rose between these two periods. Followed by sub-basin $\mathrm{JJ}(22.47 \%)$, all the indicators in this group climbed up. Sub-basin FY remained steady at $4.44 \%$, with no indicator exceeding $\pm 10 \%$.

IHA group 3 is the timing of water conditions. Julian date of minimum was ahead of time on average, especially in sub-basin $\mathrm{FH}$ and $\mathrm{MB}$; on the other hand, Julian date of minimum generally lagged in time. The biggest fluctuation in both low pulse count and low pulse duration (group 4) occurred in sub-basin DL, with a value of 15.65 and $-19.88 \%$, respectively. Followed by sub-basin MJ, with a greater frequency (low pulse count, $-14.71 \%$ ) and a shorter duration (low pulse duration, $15.79 \%$ ). Group 5 are the rate and frequency of water condition changes.

\section{Water Availability}

Based on daily flow simulation, flow rates that equaled or exceeded $50 \%\left(Q_{50}\right), 80 \%\left(Q_{80}\right)$, and $95 \%\left(Q_{95}\right)$ of the time for each year were extracted along with the long-term monthly average (Fig. 7). The difference between average flow and median flow $\left(Q_{50}\right)$ is able to indicate the frequency of flow events as higher as or lower than the average flow rate. For example, $Q_{50}$ was lower than the average flow in sub-basin MB representing that more flow events were below the average flow rate. Upstream sub-basins had lower flow rate, while downstream sub-basins had higher flow rate. The highest flow rate was in sub-basin MB, followed by sub-basin FH.

\section{Water Consumption}

Average water consumed by agriculture and industry occupied $89.62 \%$ of the total consumed water, and water consumed by domestic water use occupied $9.73 \%$, while average eco-environmental water consumption only accounted for the rest $0.65 \%$ (Fig. 8). Spatial distribution of water consumption also differed between the upstream and downstream of the YRB with higher consumption observed in the downstream sub-basins. Sub-basin DL consumed the largest amount of water with an average value of 36.33 billion cubic meters $\left(\mathrm{Bm}^{3}\right)$, followed by sub-basin $\mathrm{MB}$ $\left(23.79 \mathrm{Bm}^{3}\right)$, BL $\left(18.06 \mathrm{Bm}^{3}\right)$, and $\mathrm{FH}\left(15.53 \mathrm{Bm}^{3}\right)$. On the 


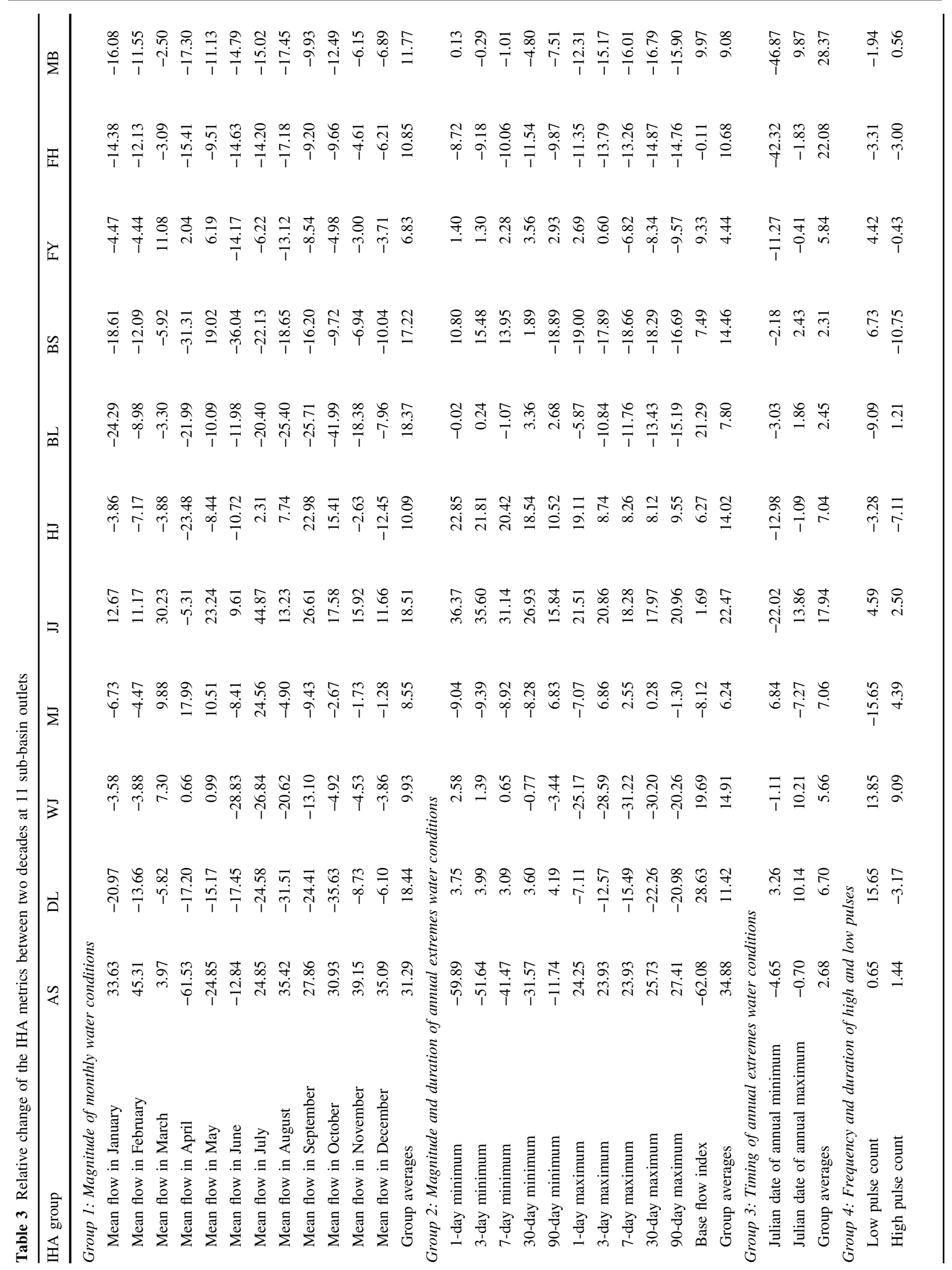




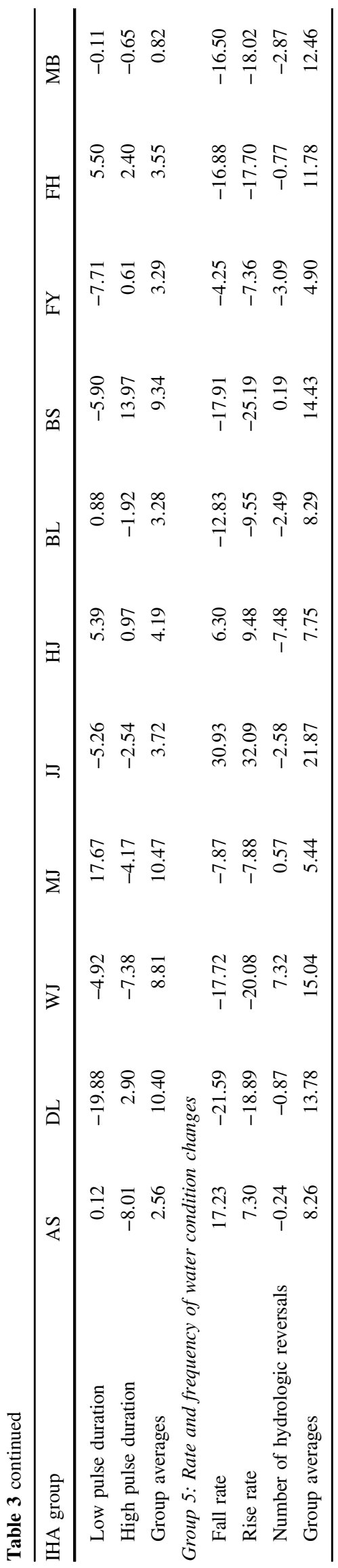

contrary, headwater sub-basin $\mathrm{AS}\left(0.21 \mathrm{Bm}^{3}\right)$ consumed the smallest amount of water.

A clearly upward trend was observed in both domestic water consumption and eco-environmental consumption in all sub-basins (Fig. 9). Whereas agro-industrial water consumption showed different trends in different sub-basins, a slightly downward trend was observed in sub-basins DL, $\mathrm{MJ}, \mathrm{WJ}$, and AS, and was found to be leveled off at subbasin BS, while consumption in the remaining six subbasins were all on the rise. Water resources consumed in agriculture and industry accounted for a large majority of water consumption. The sub-basin that was solely on the decline in total water consumption was sub-basin WJ. The individual trend was well caught by GM $(1,1)$ model, the predicted performance was satisfied.

\section{Water Vulnerability}

Water vulnerability of 11 sub-basins from 1994 to 2013 was partitioned into four categories based on threshold values (Figs. 1 and 10). Water vulnerability of sub-basins AS, FY, $\mathrm{FH}$, and $\mathrm{MB}$ were all at low level except for moderate level found in both sub-basins AS and FY. Medium-high WV and high WV appeared in the remaining sub-basins with varying frequency. High WV mostly appeared in sub-basin BS $(n=17)$, followed by sub-basin HJ $(n=5)$ and $\mathrm{JJ}(n=$ 4). Medium-high WV mostly appeared in sub-basin HJ ( $n$ $=28$ ), followed by sub-basin DL $(n=20)$, sub-basins MJ and JJ both ranked the third place with 12 medium-high WV status. High WV status was mostly found in domestic water use $(n=16)$, medium-high WV status was mostly found in agriculture and industry water use $(n=44)$, and low WV mostly appeared in eco-environmental water use $(n=206)$. No high WV was observed with respect to total water use in 20 years while more than half of the status of low WV $(n=118)$ were found in considered time period. Water status in high WV and medium-high WV both increased in the recent decade with more than doubled counts (10 high WV and 31 medium-high WV in the first decade; 21 high WV and 64 medium-high WV in the second decade).

\section{Discussion}

\section{Hydrologic Characteristics of the YRB}

Hydrologic alteration, the most important driving force of available water resources variation, explains dynamics in water resources availability. There was a clear downward tendency in water yield in 7 out of 11 sub-basins during these two decades, which would potentially pose threat to the balance of water supply and demand interaction. 
Fig. 7 Hydrographs of annual flow extracted from FDCs. a $95 \%$ exceedance $\left(Q_{95}\right)$. b 80 $\%$ exceedance $\left(Q_{80}\right)$. c $50 \%$ exceedance $\left(Q_{50}\right)$. d average $\left(Q_{\text {average }}\right)$ flow (a)

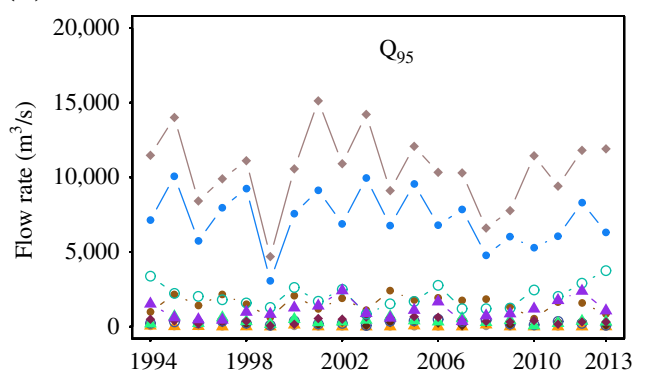

(c)

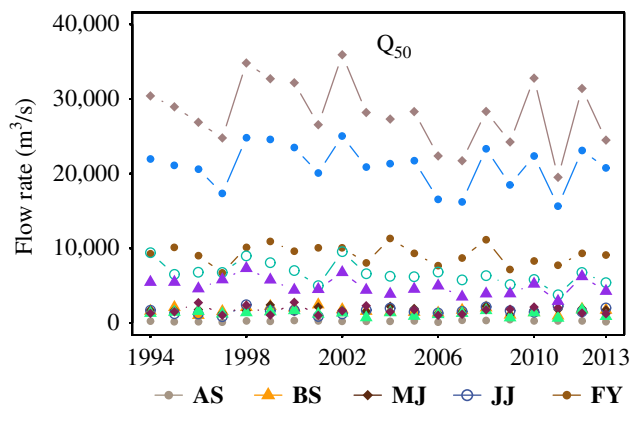

(b)

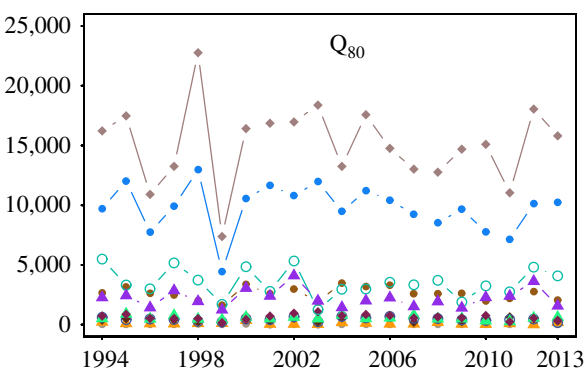

(d)

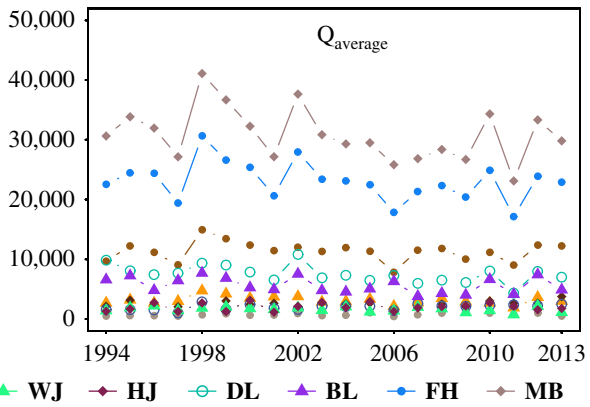

Fig. 8 Water consumption of 11 sub-basins in the YRB from 1994 to 2013

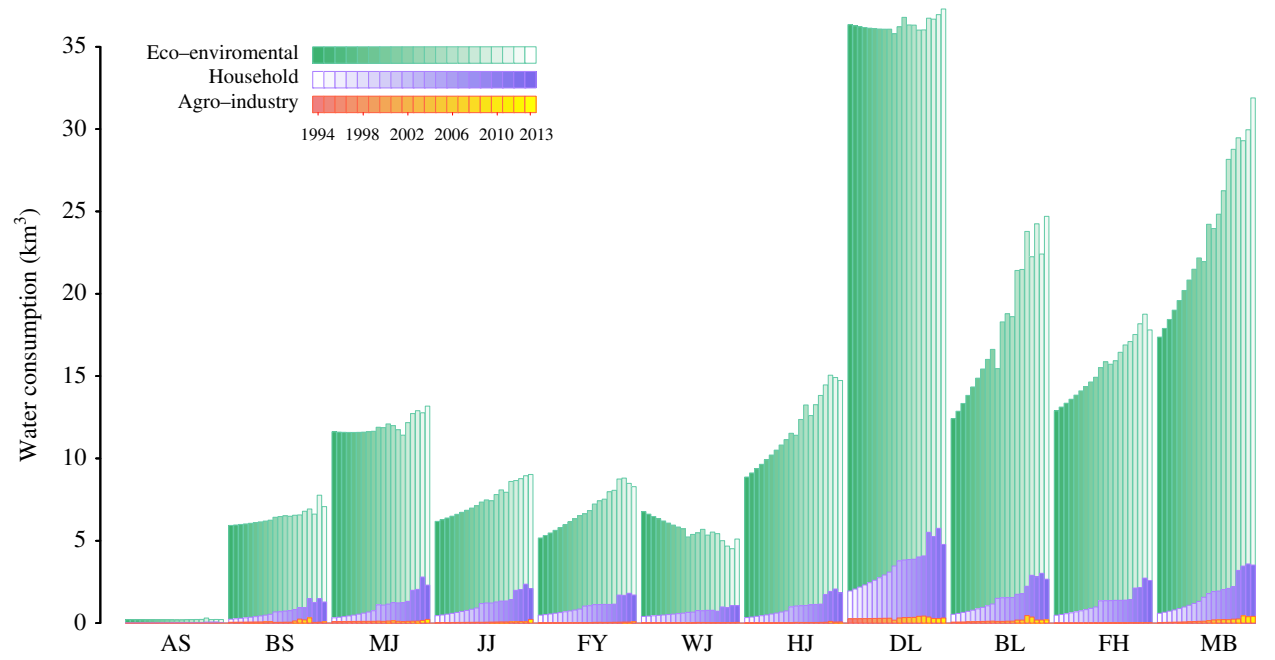

Although water yield tended to be more stable in the recent decade, the growing frequency of outliers implied a bigger chance of extreme climate condition in the recent decade in the YRB. Moreover, we found that downstream sub-basins yielded more water and had higher water yield variability. Relative differences between means were detected at 11 sub-basin outlets using IHA metrics, which served as a complement to water yield analysis in providing detailed measurement of water variation. All the months of downstream sub-basins (sub-basins DL, BL, FH, and MB) saw negative deviations in magnitude of water conditions, which added to the detected decrease in water yield in urging caution to protect the vulnerable water resources of the YRB for achieving long-term benefit.

The strong correlation between precipitation and water yield indicated a significant statistical relationship between them. It could be concluded that the spatial and temporal variation of the annual water yield was mainly attributed to the precipitation anomaly, which implied that decrease in the annual water yield resulted primarily from the decrease in annual precipitation. Larger variability in precipitation 

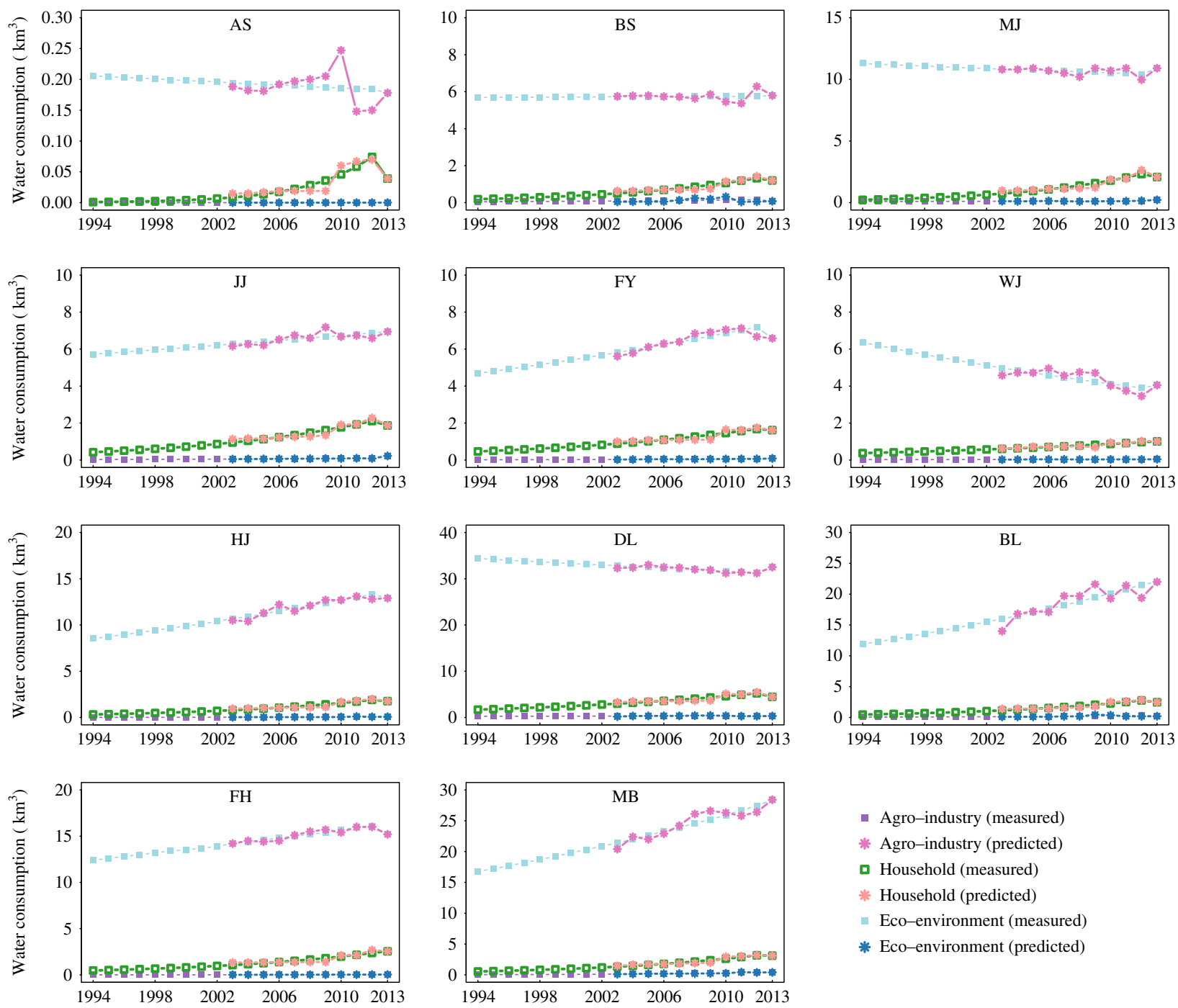

\footnotetext{
- Agro-industry (measured)

* Agro-industry (predicted)

c Household (measured)

* Household (predicted)

- Eco-environment (measured)

* Eco-environment (predicted)
}

Fig. 9 Measured and predicted water consumption of agro-industry, household and eco-environment

may bring about vulnerability in confronting natural disaster events.

\section{Spatiotemporal Water Vulnerability of the YRB}

When water vulnerability is assessed at sub-basin level on a yearly basis, both spatial distribution composed of distinct sub-basin characteristics and temporal pattern composed of unique yearly status are obtained. Although sub-basins FY, $\mathrm{FH}$, and $\mathrm{MB}$ had sufficient water to meet its aggregate annual sub-basin wide demand during these two decades, the significant decrease in available water and sustained growth in water consumption observed in these three subbasins may pose a threat for future WB. The provision of adequate and stable water to these sub-basins is extremely vital, considering their large population and fast growing economic development. Sub-basin AS is the headwater of the YRB, water resources in sub-basin AS were also able to provide adequate quantity of water to fulfill the need of its small population and low-intensity development in the mountainous headwater region.

However, the remaining sub-basins were detected with higher levels of vulnerability. In sub-basin BS, the ecoenvironmental volume (BS-L1) and domestic volume (BSL2) showed high vulnerability level, whereas water vulnerability for agro-industrial volume (BS-L3) and total volume (BS-all) showed different patterns. Flow rate in this sub-basin was very low in winter season; consequently, $Q_{95}$ and $Q_{80}$ were not sufficient to meet eco-environmental and domestic water consumed in this sub-basin. Sub-basins AS and BS are known for the abundant hydropower stored in the huge altitude difference of $5.1 \mathrm{~km}$ in the main stream of Jinsha Jiang River, which accounts for $95 \%$ of the altitude difference of the whole YRB. The fluctuation in water 


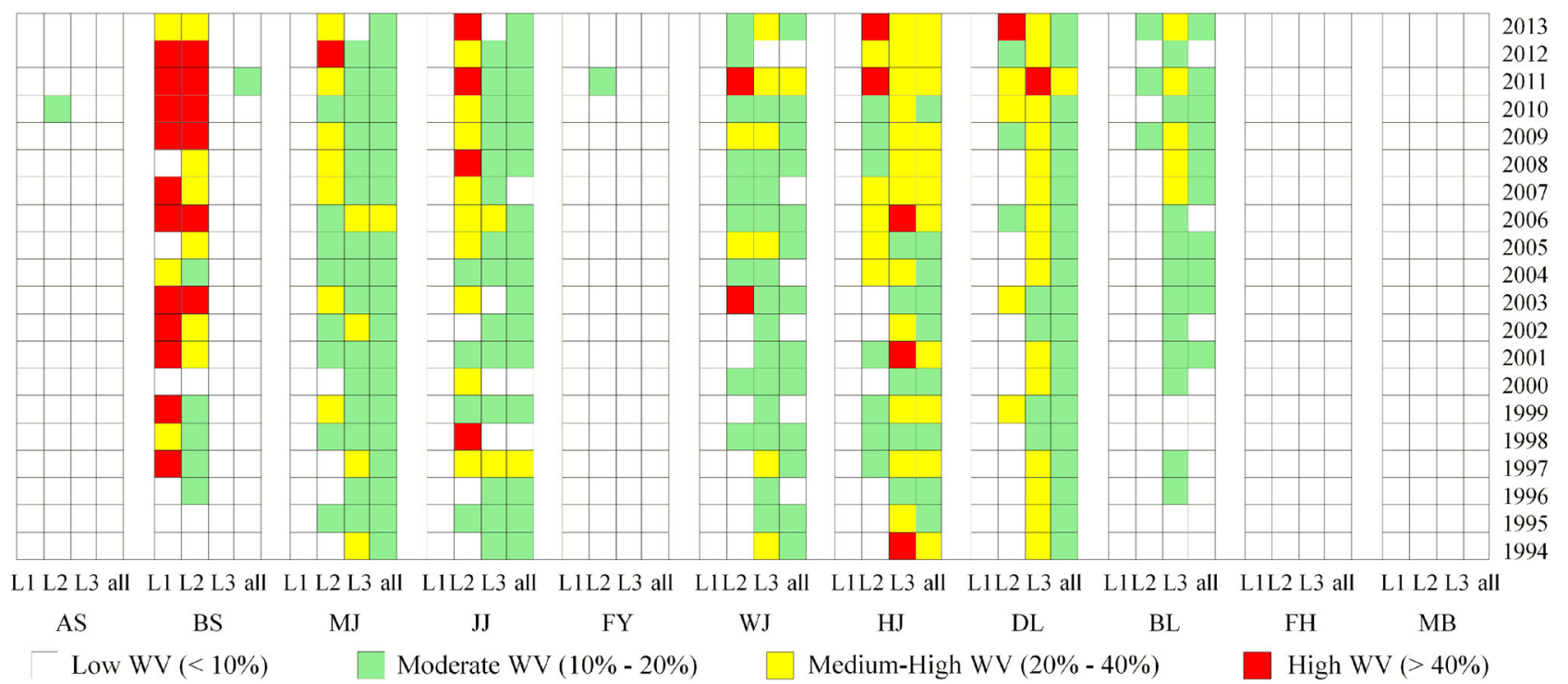

Fig. 10 Water vulnerability (WV) of 11 sub-basins in the YRB from 1994 to 2013. L1: eco-environmental water; L2: domestic water; L3: agroindustrial water; all: total water

resources may bring instability to hydropower production, and the decreasing monthly flow at sub-basin BS may exert pressure on WB.

Among the sub-basins in the YRB, sub-basin HJ was at the highest vulnerability level in terms of total WB. Despite a slight increase in average annual water yield in the later decade, the vulnerability level did not reduce. The dramatic increase in extreme low flow rate also exerted pressure on domestic water consumption, which can be seen by the darkened color in HJ-L2 along the time scale (Fig. 10). Subbasin $\mathrm{HJ}$ is the major water source of the middle project of South-to-North Water Diversion Project (Zhang et al. 2015); this massive project was partly finished and began transferring water to the northern part of China in September 2014. The designed transfer volume is $13 \mathrm{Bm}^{3}$ each year; the final destination is Beijing (the capital of China). However, the decreasing trend in water resources had already showed before the operation of this project. The climate abnormality and human activity intensity may continue to pose pressure to the HJ sub-basin in the following years, especially after the South-to-North Water Diversion Project (Zhang et al. 2015).

Sub-basin JJ is located in the east side of sub-basin HJ; water status remained stable in agro-industrial volume (JJL3) and total volume (JJ-all), which indicates that the increment in both water yield and high flow rate was able to fulfill the need for increasing agro-industrial demand in this sub-basin. Recently however, high vulnerability in domestic volume (JJ-L2) appeared more frequently. This happened because the prominent rise in low flow rate made the $Q_{80}$ fail to balance the increasing domestic water consumption. The domestic volume of sub-basin MJ (MJ-L2) was exposed to high vulnerability only in the year 2012, despite the fact that large cities such as Chengdu and Chongqing that have high industry and population density are situated in this sub-basin. In spite of total water consumption dropped in sub-basin WJ, vulnerability in WB was accelerated. Sub-basin WJ has high density of agricultural population. However, vast migration of rural workers from the countryside to the urban area from the 1990s of the last century contributes to the reduction in water consumption (Li 2003; Shi 2008). Sub-basin DL had the largest water consumption as well as water yield; nevertheless, vulnerable water status has already become a major barrier of environmental and economic development in this sub-basin (Chang et al. 2010; Dai et al. 2008).

Sub-basin BL remains the most well-protected pristine biodiversity, which may be due to the low water vulnerability status in this sub-basin. This region is one of the most important wetlands on earth, recognized by the International Union for the Conservation of Nature. The submerged aquatic plants and their rich diversity make it the heaven for hundreds of thousands of wintering birds (de Leeuw et al. 2010; Feng et al. 2012). Unfortunately, this sub-basin suffered the most dramatic decline in water yield, which may constitute one of the potential reasons for frequently reported drought events since the beginning of this century (Feng et al. 2012; Zhao et al. 2010).

Overall, the numbers of high WV and medium-high WV were more than doubled in the recent decade compared to the former decade. The strengthened vulnerability in water resources almost showed in every sub-basin of the YRB. In addition, water resources used in agriculture and industry constitute the vast majority of water consumption, and the 
volume for agro-industrial water consumption was the most vulnerable block. Comparatively, the available water volume for eco-environmental consumption was the least vulnerable block, the upward trend was clearly observed in both domestic water consumption and eco-environmental consumption in all sub-basins. The ongoing development would continue to pose a greater threat to the water sustainability of the YRB. The increasing conflict between availability and consumption in the YRB is projected to continue. Trend in water resources status results may shed light in the near future in the basin.

\section{Advantages and Potential Limitations}

This research has promoted water vulnerability assessment in several aspects. Firstly, contrary to existing water vulnerability methods that mainly focus on assessing stationary status, the application of the EHA model in the YRB captures the dynamic variation of water vulnerability from 1994 to 2013 with a high temporal resolution (yearly) and predicts potential trends of future water status. Secondly, compared to the frequently employed administrative boundary of most existing assessing tools, the EHA model assesses water vulnerability at sub-basin level within the biophysical boundary, which leads to a better interpretation of water vulnerability. Thirdly, consideration of the linkage of hydrologic alteration, water availability, and water consumption allows a collection of data and knowledge about many aspects of water resources to be more effectively applied to vulnerability assessment. The supply-demand relationship gives straightforward insight about the driving forces of water scarcity. Integrated assessment of water resources that comprises the interactive relationship between supply and demand of water presents a new perspective of water vulnerability.

The improvements of method that bring these advantages can only be expected using the multi-model ensemble; however, at the same time uncertainty is introduced. Generally, uncertainty exists in the configuration of the physical system, including SWAT model inputs, the extraction of available water resources, and the calculation of water consumption. Although hydrologic models, only an approximation of reality, are increasingly more complex and capable of modeling and assessing complex hydrologic processes, it is seldom practical to eliminate all sources of uncertainty completely.

In addition, this study needs a collection of data to be synthesized for vulnerability assessment. However, data scarcity is a common problem in hydrological modeling and assessment, especially for basins with large area (Bangash et al. 2012; Candela et al. 2012; Legesse et al. 2003; Xie and Cui 2011). The YRB also suffers from scarce data availability. Although with limited data, the observed hydrologic trend in this paper is consistent with other assessment researches conducted in the YRB, the hydrologic assessment result is convincible.

\section{Conclusion}

In order to allocate water in a reasonable and efficient way, a better understanding of water status across heterogeneous basins is needed. In this paper, a group of hydrologic techniques was carefully organized and successfully implemented to facilitate evaluation of water vulnerability status of the YRB, which is described as the EHA model. Evaluating water vulnerability from an integrated perspective of hydrologic alteration, water availability, and water consumption at sub-basin level, general hydrologic characteristics of the basin itself and distinct rule of each subbasin were observed.

Strengthened water vulnerability was observed in all subbasins in the YRB, which was driven by both noteworthy reduction in available water resources and remarkable increase in consumed water. The demand of water resources is expected to grow in the near future especially with the promotion of the Chinese government. Under the circumstances of global climate change and basinal economic growth, water managers and economic planners should understand more about the status and future potential changes in the water sector, and ensure maximum degree of flexibility in their water management operations. Highly vulnerable sub-basins may require both supply and demand management in the future to balance the deficit. The differences in water condition among sub-basins suggest the need for an integrated basin-wide approach that considers unique feature of each sub-basin in water resource management in the YRB. Moreover, the society should be able to take action to prepare themselves for future conditions, increase their ability in confronting water vulnerability and cooperate their efforts in improving water security.

Acknowledgments The authors thank Mr. Jun Wang (Director of Bureau of Hydrology, CWRC, Wuhan, China) for providing the valuable historical observed runoff data of the YRB. We are grateful to Robert Twiss (Emeritus Professor of University of California, Berkeley, San Francisco, USA) for contributing to the engaged discussions and comments, and suggestions during the preparation of this paper. The Science and Technology Commission of Shanghai Municipality (no. 15DZ1203606) and the Shanghai Key Lab for Urban Ecological Processes and Eco-Restoration (no. SHUES2015B02) funded this work. The authors thank the editor and the anonymous reviewers who helped to improve this paper with their thorough review. 


\section{Compliance with ethical standards}

Conflict of interest The authors declare that they have no conflict of interest.

\section{References}

Akay D, Atak M (2007) Grey prediction with rolling mechanism for electricity demand forecasting of Turkey. Energy 32:1670 1675

Alessa L, Kliskey A, Lammers R, Arp C, White D, Hinzman L, Busey R (2008) The arctic water resource vulnerability index: an integrated assessment tool for community resilience and vulnerability with respect to freshwater. Environ Manage 42:523-541

Arnold JG, Kiniry JG, Srinivasan R (2013) Soil and Water Assessment Tool input/output documentation version 2012. http://swat.tamu. edu/documentation/. Accessed 20 Jun 2016

Bangash RF, Passuello A, Hammond M, Schuhmacher M (2012) Water allocation assessment in low flow river under data scarce conditions: a study of hydrological simulation in Mediterranean basin. Sci Total Environ 440:60-71

Bierkens MFP (2015) Global hydrology 2015: state, trends, and directions. Water Resour Res 51:4923-4947

Botter G, Basso S, Porporato A, Rodriguez-Iturbe I, Rinaldo A (2010) Natural streamflow regime alterations: damming of the Piave river basin (Italy). Water Resour Res 46.

Candela L, Tamoh K, Olivares G, Gomez M (2012) Modelling impacts of climate change on water resources in ungauged and data-scarce watersheds. Sci Total Environ 440:253-260

Castellarin A, Galeati G, Brandimarte L, Montanari A, Brath A (2004) Regional flow-duration curves: reliability for ungauged basins. Adv Water Resour 27:953-965

Castillo CR, Güneralp İ, Güneralp B (2014) Influence of changes in developed land and precipitation on hydrology of a coastal Texas watershed. Appl Geogr 47:154-167

Chang J, Li J, Lu D, Zhu X, Lu C, Zhou Y, Deng C (2010) The hydrological effect between Jingjiang River and Dongting Lake during the initial period of Three Gorges Project operation. J Geogr Sci 20:771-786

Chaves HM, Alipaz S (2007) An integrated indicator based on basin hydrology, environment, life, and policy: the watershed sustainability index. Water Resour Manage 21:883-895

Chen H, Guo S, Xu C, Singh VP (2007) Historical temporal trends of hydro-climatic variables and runoff response to climate variability and their relevance in water resource management in the Hanjiang basin. J Hydrol 344:171-184

Cohen A, Sullivan CA (2010) Water and poverty in rural China: developing an instrument to assess the multiple dimensions of water and poverty. Ecol Econ 69:999-1009

Dai Z, Du J, Li J, Li W, Chen J (2008) Runoff characteristics of the Changjiang River during 2006: effect of extreme drought and the impounding of the Three Gorges Dam. Geophys Res Lett 35

Dawadi S, Ahmad S (2013) Evaluating the impact of demand-side management on water resources under changing climatic conditions and increasing population. J Environ Manage 114:261-275

de Grosbois D, Plummer R (2015) Problematizing water vulnerability indices at a local level: a critical review and proposed solution. Water Resour Manage 29:5015-5035

de Leeuw J, Shankman D, Wu G et al. (2010) Strategic assessment of the magnitude and impacts of sand mining in Poyang Lake, China. Region Environ Change 10:95-102

Deng J (1982) Control problems of grey systems. Syst Control Lett $1: 288-294$
Deng J (1989) Introduction to grey system theory. J Grey Syst 1:1-24

Dessu SB, Melesse AM, Bhat MG, McClain ME (2014) Assessment of water resources availability and demand in the Mara River Basin. Catena 115:104-114

Dickson SE, Schuster-Wallace CJ, Newton JJ (2016) Water security assessment indicators: the rural context. Water Resour Manage 30:1567-1604

Draper AJ, Jenkins MW, Kirby KW, Lund JR, Howitt RE (2003) Economic-engineering optimization for California water management. J Water Resour Plan Manage 129:155-164

Feng L, Hu C, Chen X, Cai X, Tian L, Gan W (2012) Assessment of inundation changes of Poyang Lake using MODIS observations between 2000 and 2010. Remote Sens Environ 121:80-92

Fukunaga DC, Cecilio RA, Zanetti SS, Oliveira LT, Caiado MAC (2015) Application of the SWAT hydrologic model to a tropical watershed at Brazil. Catena 125:206-213

Gao B, Yang D, Zhao T, Yang H (2012) Changes in the eco-flow metrics of the Upper Yangtze River from 1961 to 2008. J Hydrol 448:30-38

Gao Y, Vogel RM, Kroll CN, Poff NL, Olden JD (2009) Development of representative indicators of hydrologic alteration. J Hydrol 374:136-147

Guan Y, Zhang X, Zheng F, Wang B (2015) Trends and variability of daily temperature extremes during 1960-2012 in the Yangtze River Basin, China. Global Planet Change 124:79-94

Hamouda MA, El-Din MMN, Moursy FI (2009) Vulnerability assessment of water resources systems in the Eastern Nile Basin. Water Resour Manage 23:2697-2725

Hsu C, Chen C (2003) Applications of improved grey prediction model for power demand forecasting. Energ Convers Manage 44:2241-2249

Kayacan E, Ulutas B, Kaynak O (2010) Grey system theorybased models in time series prediction. Expert Syst Appl 37:1784-1789

Lahoz WA, De Lannoy GJM (2014) Closing the gaps in our knowledge of the hydrological cycle over land: conceptual problems. Surv Geophy 35:623-660

Lawrence PR, Meigh J, Sullivan C (2002) The water poverty index: an international comparison. Department of Economics, Keele University.

Legesse D, Vallet-Coulomb C, Gasse F (2003) Hydrological response of a catchment to climate and land use changes in Tropical Africa: case study South Central Ethiopia. J Hydrol 275:67-85

Li Q (2003) An analysis of push and pull factors in the migration of rural workers in China. Social Sci China 1:125-136

Mathews R, Richter BD (2007) Application of the indicators of hydrologic alteration software in environmental flow setting. J Am Water Resour Assoc 43:1400-1413

Mejía A, Rossel F, Gironás J, Jovanovic T (2015) Anthropogenic controls from urban growth on flow regimes. Adv Water Resour $84: 125-135$

Moriasi D, Arnold J, Van Liew M, Bingner R, Harmel R, Veith $T$ (2007) Model evaluation guidelines for systematic quantification of accuracy in watershed simulations. Trans ASABE 50:885-900

Neitsch SL, Kiniry JG, Williams JR (2009) Soil And Water Assessment Tool theoretical documentation version 2009. http://swat. tamu.edu/media/99192/swat2009-theory.pdf. Accessed 20 Jun 2016

Nyerges T (2002) Linked visualizations in sustainability modeling: an approach using participatory GIS for decision support. Assoc Am Geog Illust, Los Angeles 18.

Palmer MA, Lettenmaier DP, Poff NL, Postel SL, Richter B, Warner R (2009) Climate change and river ecosystems: protection and adaptation options. Environ Manage 44:1053-1068 
Palmer MA, Reidy Liermann CA, Nilsson C, Flörke M, Alcamo J, Lake PS, Bond N (2008) Climate change and the world's river basins: anticipating management options. Front Ecol Environ 6:81-89

Plummer R, de Grosbois D, Armitage D, de Loe RC (2013) An integrative assessment of water vulnerability in First Nation communities in Southern Ontario, Canada. Global Environ Change 23:749-763

Plummer R, de Loe R, Armitage D (2012) A systematic review of water vulnerability assessment tools. Water Resour Manage 26:4327-4346

Pradhanang SM, Mukundan R, Schneiderman EM et al. (2013) Streamflow responses to climate change: analysis of hydrologic indicators in a New York City water supply watershed. J Am Water Resour Assoc 49:1308-1326

Ravazzani G, Barbero S, Salandin A, Senatore A, Mancini M (2015) An integrated hydrological model for assessing climate change impacts on water resources of the Upper Po River Basin. Water Resour Manage 29:1193-1215

Richter B, Baumgartner J, Wigington R, Braun D (1997) How much water does a river need?. Freshwater Biol 37:231-249

Richter BD, Baumgartner JV, Braun DP, Powell J (1998) A spatial assessment of hydrologic alteration within a river network. Regul River 14:329-340

Richter BD, Baumgartner JV, Powell J, Braun DP (1996) A method for assessing hydrologic alteration within ecosystems. Conserv Biol 10:1163-1174

Richter BD, Mathews R, Wigington R (2003) Ecologically sustainable water management: managing river flows for ecological integrity. Ecol Appl 13:206-224

Rouholahnejad E, Abbaspour KC, Srinivasan R, Bacu V, Lehmann A (2014) Water resources of the Black Sea Basin at high spatial and temporal resolution. Water Resour Res 50:5866-5885

Shi L (2008) Rural migrant workers in China: scenario, challenges and public policy. ILO, Geneva

Shiklomanov IA (1996) Comprehensive assessment of the freshwater resources of the world: assessment of water resources and water availability in the world. UN.

Shrestha RR, Peters DL, Schnorbus MA (2014) Evaluating the ability of a hydrologic model to replicate hydro-ecologically relevant indicators. Hydrol Process 28:4294-4310

Singh A (2014) Conjunctive use of water resources for sustainable irrigated agriculture. J Hydrol 519:1688-1697

Singh A, Panda SN (2012) Effect of saline irrigation water on mustard (Brassica Juncea) crop yield and soil salinity in a semi-arid area of North India. Exp Agric 48:99-110
State Council of China (2014) Promoting the development of Yangtze River Basin. http://www.gov.cn/zhengce/content/2014-09/25/ content_9092.htm. Accessed 20 Jun 2016

Sullivan CA (2011) Quantifying water vulnerability: a multi-dimensional approach. Stoch Environ Res Risk Assess 25:627-640

Sullivan CA, Cohen A, Faurès J-M, Santini G (2010) The rural water livelihoods index. http://www.fao.org/nr/water/docs/ FAOW_RWLI_paper.pdf. Accessed 20 Jun 2016

Sullivan CA, Meigh J (2007) Integration of the biophysical and social sciences using an indicator approach: Addressing water problems at different scales. Water Resour Manage 21:111-128

Sunday RKM, Masih I, Werner M, van der Zaag P (2014) Streamflow forecasting for operational water management in the Incomati River Basin, Southern Africa. Phys Chem Earth 72:1-12

United Nations (2015) World population prospects: 2015 revision population database. http://www.un.org/esa/population/unpop. htm. Accessed 20 Jun 2016

Vörösmarty CJ, Green P, Salisbury J, Lammers RB (2000) Global water resources: vulnerability from climate change and population growth. Science 289:284-288

Vogel RM, Fennessey NM (1994) Flow-duration curves. I: new interpretation and confidence intervals. J Water Resour Plann Manage 120:485-504

Vogel RM, Fennessey NM (1995) Flow duration curves II: a review of applications in water resources planning. J Am Water Resour Assoc 31:1029-1039

Wang W, Shao Q, Yang T, Peng S, Xing W, Sun F, Luo Y (2013) Quantitative assessment of the impact of climate variability and human activities on runoff changes: a case study in four catchments of the Haihe River basin, China. Hydrol Process 27:1158-1174

Xi X, Poh KL (2015) A novel integrated decision support tool for sustainable water resources management in Singapore: synergies between system dynamics and analytic hierarchy process. Water Resour Manage 29:1329-1350

Xie X, Cui Y (2011) Development and test of SWAT for modeling hydrological processes in irrigation districts with paddy rice. $\mathrm{J}$ Hydrol 396:61-71

Zhang S, Yang D, Xu X (2015) Driving factors for runoff decline in the Upper Hanjiang basin, a major water source for the South-toNorth Water Diversion Project in China. Proc Int Assoc Hydrol Sci 368:63-68

Zhao G, Hoermann G, Fohrer N, Zhang Z, Zhai J (2010) Streamflow trends and climate variability impacts in Poyang Lake Basin, China. Water Resour Manage 24:689-706 